\title{
Examination of steam gasification of coal with physically mixed catalysts
}

\author{
Katarzyna Śpiewak, Grzegorz Czerski*, Agnieszka Sopata \\ AGH University of Science and Technology, Faculty of Energy and Fuels, al. Mickiewicza 30, 30-059, Krakow, Poland \\ "Corresponding author: e-mail: gczerski@agh.edu.pl
}

\begin{abstract}
The aim of this study was to analyse the steam gasification process of 'Janina' coal with and without Na-, K- and Ca-catalysts. The catalysts were physically mixed with the coal due to the simplicity of this method, short time of execution and certainty that the amount of catalyst is exactly as the adopted one. The isothermal measurements were performed at 800,900 and $950^{\circ} \mathrm{C}$ and a pressure of $1 \mathrm{MPa}$ using thermovolumetric method. The obtained results enabled assessment of the effect of analysed catalysts on the process at various temperatures by determination of: i) carbon conversion degree; ii) yield and composition of the resulting gas; and iii) kinetics of formation reactions of main gas components - $\mathrm{CO}$ and $\mathrm{H}_{2}$. The addition of catalysts, as well as an increase in operating temperature, had a positive effect on the coal gasification process - reactions rates increased, and the process time was reduced.
\end{abstract}

Keywords: coal gasification, kinetics, catalysts.

\section{INTRODUCTION}

The energy sector is facing a huge challenge of meeting the growing demand for energy while keeping the acceptable standards associated with the emission of flue gases ${ }^{1}$. This problem is particularly important in the case of coal, considered as "dirty" fuel. Nevertheless, coal provides one-third of the energy consumed worldwide and, despite legitimate concerns about air pollution, will remain an important source of energy in the future ${ }^{2}$. Therefore, greater efforts are needed to develop efficient technologies of coal conversion, including coal gasification technology. Worldwide, there are many gasification plants for energy and chemical production, but their development through the addition of a catalyst is not applicable on an industrial scale. It results from the fact that catalytic gasification involves additional cost, and the impact of catalysts is difficult to predict since it depends on numerous factors ${ }^{3}$. However, these drawbacks may be compensated by the significant advantages associated with the use of catalysts, such as: acceleration of the process, reduction of its temperature and duration while maintaining high carbon conversion degree (especially important in the case of fluidised bed gasifiers), and possibility of adjusting composition of the obtained gas depending on its further utilization ${ }^{4}$. These advantages can be obtained by using very cheap compounds (e.g. minerals commonly found in nature, such as halite or calcite $\left.{ }^{5,6}\right)$ containing alkali or alkaline earth metals, which are considered as one of the most promising catalysts for gasification ${ }^{7}$. Moreover, it is possible to combine these catalysts with coal in a very inexpensive and simple way, i.e. by physical mixing ${ }^{8}$. Nevertheless, the catalytic effect has to be assessed on a case-by-case basis since it depends on numerous factors, such as type and amount of catalyst, process conditions, properties of coal used, etc ${ }^{3}$. Therefore, it is necessary to perform a detailed analysis of the effect of catalysts, that have a real chance to be used on an industrial scale, on gasification of suitable coal. Comprehensive analysis should take into account the entire process (both pyrolysis and char gasification stages), while most of the scientific research is focused solely on the latter stage (pyrolysis, which has a significant impact on the process, is omitted) ${ }^{9}$. Moreover, a reliable assessment of catalytic gasification process should take into account both efficiency and selectivity of catalysts used. Only such a detailed analysis will allow taking further steps to use catalysts on an industrial scale.

Due to the above, the detailed analysis of the effect of catalysts on the steam coal gasification process was performed. Sodium, potassium and calcium nitrates in the amount of $3 \mathrm{wt} . \%$ of active material were used as catalysts and were physically mixed with raw 'Janina' coal. The selection of coal type and catalysts amount was based on previous works of the Authors ${ }^{10,11,12}$. A series of catalytic and non-catalytic isothermal measurements at various temperatures and under elevated pressure was carried out using a unique thermovolumetric equipment ${ }^{13}$. Based on the obtained results, the followings were determined: changes in the formation rates of gaseous components $\left(\mathrm{CO}, \mathrm{H}_{2}, \mathrm{CO}_{2}, \mathrm{CH}_{4}\right)$, carbon conversion degree as well as yield and composition of the resulting gas. Moreover, kinetics analysis of the formation reactions of two basic gas components $\left(\mathrm{CO}\right.$ and $\left.\mathrm{H}_{2}\right)$ was carried out, including calculation of half-times and rate constants of these reactions. In the last step, the kinetic parameters of the $\mathrm{CO}$ and $\mathrm{H}_{2}$ formation reactions were calculated using three models (isoconversional method, grain model - GM, and random pore model - RPM). The obtained results enabled a comprehensive assessment of the effect of catalysts (efficiency and selectivity) on the steam gasification of coal at various temperatures.

\section{MATERIAL AND METHODS}

\section{Material, equipment and methodology of examinations}

Bituminous Polish coal from 'Janina' mine was selected for investigation. Characteristics of this coal, including proximate and ultimate analyses, as well as composition of ash, is presented in Table 1.

The results of proximate and ultimate analyses indicate that 'Janina' is low-rank bituminous coal and, as evidenced by the previous research ${ }^{14}$, belongs to relatively reactive coals. Moreover, ash contains oxides of metals catalysing the gasification process, such as $\mathrm{Mg}, \mathrm{Ca}, \mathrm{Na}$ or $\mathrm{K}$, but its main components are $\mathrm{SiO}_{2}$ and $\mathrm{Al}_{2} \mathrm{O}_{3}$ that inhibit the process. Therefore, in catalytic measurements samples of 
Table 1. Characteristic of 'Janina' coal and ash composition

\begin{tabular}{|c|c|c|c|c|c|}
\hline \multicolumn{2}{|c|}{ Proximate analysis [wt $\%$ ] } & \multicolumn{2}{|c|}{ Ultimate analysis [wt\%] } & \multicolumn{2}{|c|}{ Ash composition [wt\%] } \\
\hline $\begin{array}{c}\text { Moisture }^{\text {ad }} \\
\text { Ash }^{\text {ad }} \\
\text { Volatile Matter }^{\text {daf }} \\
\text { Fixed Carbon }^{\text {ad }}\end{array}$ & $\begin{array}{r}8.7 \\
14.0 \\
46.1 \\
41.7\end{array}$ & $\begin{array}{l}\mathrm{C}^{\text {daf }} \\
\mathrm{H}^{\text {daf }} \\
\mathrm{S}^{\text {daf }} \\
\mathrm{N}^{\text {daf }} \\
\mathrm{O}^{\text {daf }}\end{array}$ & $\begin{array}{r}77.8 \\
3.9 \\
1.3 \\
1.1 \\
15.9\end{array}$ & $\begin{array}{c}\mathrm{SiO}_{2} \\
\mathrm{Al}_{2} \mathrm{O}_{3} \\
\mathrm{Fe}_{2} \mathrm{O}_{3} \\
\mathrm{MgO} \\
\mathrm{CaO} \\
\mathrm{K}_{2} \mathrm{O} \\
\mathrm{Na}_{2} \mathrm{O}\end{array}$ & $\begin{array}{r}59.4 \\
23.3 \\
8.2 \\
1.2 \\
2.2 \\
2.9 \\
2.8\end{array}$ \\
\hline
\end{tabular}

ad - air-dried state; ${ }^{\text {daf }}$ - dry and ash-free state; ${ }_{t}$ - total

coal with an additional 3 wt.\% of $\mathrm{Na}, \mathrm{K}$ and $\mathrm{Ca}$ (added in the form of nitrates by physical mixing) were used.

The schematic diagram of laboratory equipment, on which the measurements were carried out, is shown in Figure 1. The equipment consists of several basic systems: high-pressure reactor with a heating system; a system for feeding the reactor with a gasifying agent (steam), carrier gas (argon), and coal; a system for collecting and purifying the resulting gas; and gas analysis system. After stabilising the conditions of measurement, a coal sample is introduced onto the retort grate by piston feeder. The system for feeding steam and argon to the reaction zone is composed of micropump, steam generator, compressed gas cylinders with argon, a set of valves and flow rate regulator. The resulting gas is cooled, then cleared and dried on the filter. After decompression, the contents of $\mathrm{CO}, \mathrm{CO}_{2}$ and $\mathrm{CH}_{4}$ are continuously controlled by the automatic analyser. Besides, the content of $\mathrm{H}_{2}$ is analysed using gas chromatographs equipped with thermal conductivity detector (TCD).

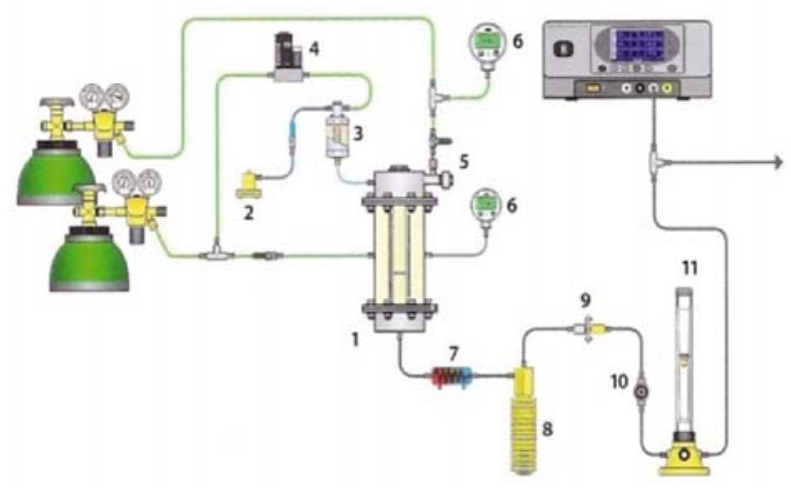

Figure 1. The laboratory equipment for kinetic examinations of coal gasification process: 1 - reactor, 2 - water pump, 3 - steam generator, 4 - mass flowmeter, 5 - coal feeder, 6 - manometer, 7 - cooler, 8 condensate tank, 9 - filter, 10 - pressure regulator, 11 - rotameter

Isothermal measurements were carried out at three temperatures 800,900 and $950^{\circ} \mathrm{C}$ under pressure of $1 \mathrm{MPa}$. Mass of the sample fed into the retort was 1 $\mathrm{g}$, and its particle size was below $0.2 \mathrm{~mm}$. The flow of steam during the measurements was equal to $3 \mathrm{~g} / \mathrm{min}$, whereas argon flow was $2 \mathrm{dm}^{3} / \mathrm{min}$.

\section{Methodology of calculations}

Based on the concentrations of the main components of the resulting gas $\left(\mathrm{CO}, \mathrm{H}_{2}, \mathrm{CO}_{2}\right.$, and $\left.\mathrm{CH}_{4}\right)$, the formation rates, as well as yield and percentage share of gaseous products, were determined. Moreover, the carbon conversion degrees CCD were calculated based on the equation (1):

$\mathrm{CCD}(\mathrm{t})=\frac{\left[\mathrm{v}_{\mathrm{Co}}(\mathrm{t})+\mathrm{V}_{\mathrm{CO}_{2}}(\mathrm{t})+\mathrm{V}_{\mathrm{CH}_{4}}(\mathrm{t})\right] \cdot \mathrm{M}_{\mathrm{C}}}{\mathrm{V}_{\mathrm{mol}} \cdot \mathrm{m} \cdot \mathrm{Cl}^{\mathrm{daf}}} \cdot 100 \%$

where:

$\mathrm{V}_{\mathrm{CO}}(\mathrm{t})+\mathrm{V}_{(\mathrm{CO} 2)}(\mathrm{t})+\mathrm{V}_{(\mathrm{CH} 4)}(\mathrm{t})$ represents volumes of released gas components, $\mathbf{M}_{\mathrm{c}}$ is a molar mass of $\mathrm{C}$ element, $\mathrm{m}$ states for mass of sample, $\mathrm{C}^{\mathrm{daf}}$ is content of carbon in sample in dry and ash-free state and $V_{\text {mol }}$ states for volume of one mole of gas at $0^{\circ} \mathrm{C}$ and $101.325 \mathrm{kPa}$.

Further kinetics analysis was conducted for the main components of the gas - carbon monoxide and hydrogen. The time required to transfer gas from the reaction zone to the analyser has been taken into account.

The progress of formation reactions $X(t)$ of $\mathrm{CO}$ and $\mathrm{H}_{2}$ may be expressed $\mathrm{as}^{15}$.

$X(t)=\frac{V_{x(t)}}{V_{x(t o t a l)}}$

where:

$V_{x(t)}$ is a volume of $\mathrm{CO}$ or $\mathrm{H}_{2}$ formed from the beginning of the reaction to time $\mathrm{t}$, and $V_{x(\text { total })}$ is total volume of $\mathrm{CO}$ or $\mathrm{H}_{2}$ formed during the whole reaction.

To analyse the kinetics of the gasification process, two approaches were used. Firstly, isoconversional method (eq. 3) was applied ${ }^{15}$.

$\ln (t)=\ln \left(\frac{f(X)}{C^{n} A}\right)+\frac{E_{a}}{R T}$

where:

$A$ is pre-exponential factor, $E_{a}$ is activation energy, $T$ is temperature, $R$ is gas constant, $n$ is an order of the reaction taking into account the concentration of the gas reactant $C$ and $\mathrm{f}(\mathrm{X})$ accounts for physical or chemical changes occurring with the progress of the reaction. Equation (3) allows to determine the activation energy from the slope of $\ln (t)=f(1 / T)$ for $\mathrm{X}=0.25,0.5,0.75$, even though $f(X)$ is unknown.

In the second approach, two models usually used to describe the heterogeneous gas-solid reaction were used: grain model and random pore model. Experimental data were analysed in the range of $\mathrm{CO}$ and $\mathrm{H}_{2}$ formation reactions from 0 to $80 \%$.

GM (eq.4) assumes that reaction occurs at the external surface of char particle and surface area decreases nonlinearly with an increase in the reaction degree ${ }^{\mathbf{1 6}}$, while according to RPM (eq.5) gasification rate initially increase and then decline based on the assumptions that particle size is constant, but its density shrinks ${ }^{17}$.

$\frac{\mathrm{dX}}{\mathrm{dt}}=\mathrm{k}_{\mathrm{GM}}(1-\mathrm{X})^{\frac{2}{3}}$
$\frac{\mathrm{dX}}{\mathrm{dt}}=\mathrm{k}_{\mathrm{RPM}}(1-\mathrm{X}) \sqrt{1-\psi \cdot \ln (1-\mathrm{X})}$ 
where:

$k_{G M} / k_{R P M}$ are reaction rate constants calculated based on GM/RPM, $\psi$ represents a parameter describing the internal structure of the non-converted particle char.

\section{RESULTS AND DISCUSSION}

\section{Formation rates of gaseous components}

Changes in the formation rates of gas components, on the example of the catalytic and non-catalytic measurements at $800^{\circ} \mathrm{C}$, are graphically presented in Figure 2. addition of catalysts resulted in a significant reduction of process time while increasing the rates of products formation during the char gasification stage (especially in the case of Na-catalyst). In turn, no unambiguous effect of catalysts on the formation rates of gas components during the pyrolysis stage was observed.

\section{Carbon conversion degree (CCD)}

To assess the effect of catalysts on the gasification process, changes in the carbon conversion degree supplemented with times of partial $(50 \%)$ conversion $\tau_{0.5}$ during
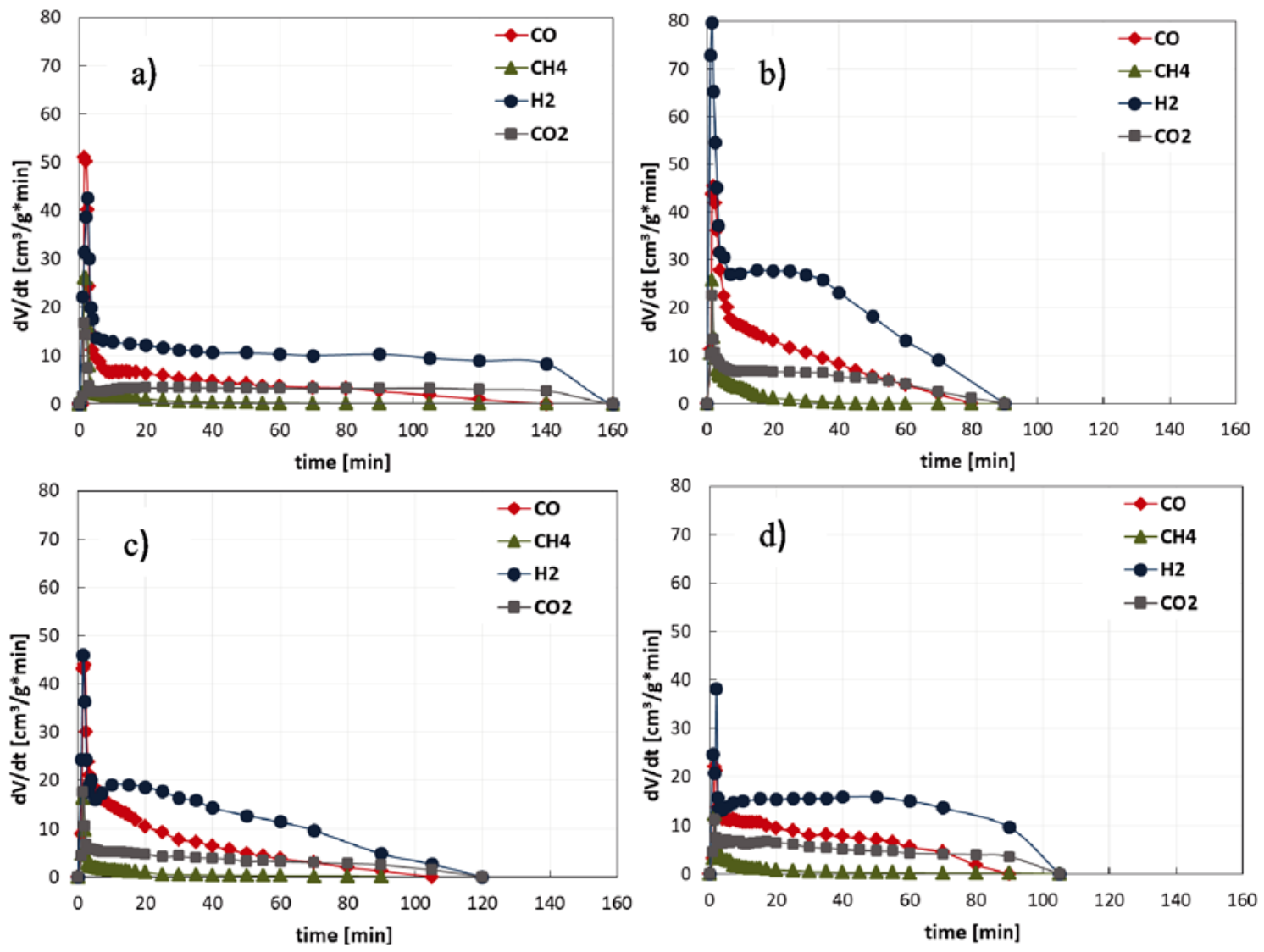

Figure 2. Changes in the formation rates of gaseous components during gasification of: a) coal; b) coal with Na-catalyst; c) coal with K-catalyst; d) coal with Ca-catalyst

The gasification process can be divided into two stages: 1) initial, lasting a few minutes pyrolysis stage in which formation rates of all analysed components were the highest, followed by 2) slower and longer stage of gasification of char formed during the pyrolysis. The latter stage is essential and determines the length of the entire process. In the gasification stage, due to the char-steam reaction, the main components of the obtained gas $\left(\mathrm{CO}\right.$ and $\left.\mathrm{H}_{2}\right)$ were formed, whereas the other components $\left(\mathrm{CO}_{2}\right.$, small amounts of $\left.\mathrm{CH}_{4}\right)$ were created as a result of secondary reactions. During the gasification stage, hydrogen was characterised by the highest formation rates, followed by carbon monoxide and carbon dioxide. In turn, formation rates of $\mathrm{CH}_{4}$ were minimal or, in some cases, methane was not created. It can also be seen that secondary reactions of $\mathrm{CO}_{2}$ and $\mathrm{H}_{2}$ formation (such as, e.g. homogeneous water gas shift reaction) took place longer than the basic heterogenous steam-char gasification reaction that results in $\mathrm{CO}$ formation. Moreover, the presented results show that the catalytic and non-catalytic gasification measurements at all examined temperatures, are presented in Figure 3.

All the presented curves had a similar character. In the first minutes of the process, rapid growth of the conversion degree (related to the pyrolysis stage) was observed. For this reason, times of partial (50\%) carbon conversion $\tau_{0.5}$ were much lower than the whole process time. Then the individual curves diverge, which indicates a varied course of the proper gasification stage. The last horizontal part of the conversion curves is identified with the subsiding of the gasification reactions.

During the non-catalytic gasification at $800^{\circ} \mathrm{C}, 77 \%$ of carbon was converted within $160 \mathrm{~min}$. The addition of catalysts caused a significant reduction in the process time while increasing the maximum carbon conversion degree. Na-catalyst turned out to be the most efficient additive at this temperature $(\mathrm{CCD}=89 \%$ within 90 $\mathrm{min}$ ). The presence of other catalysts resulted in CCDs of about $80 \%$, but the measurement with Ca-catalyst was shorter than with K-catalyst. An increase in tem- 
a)

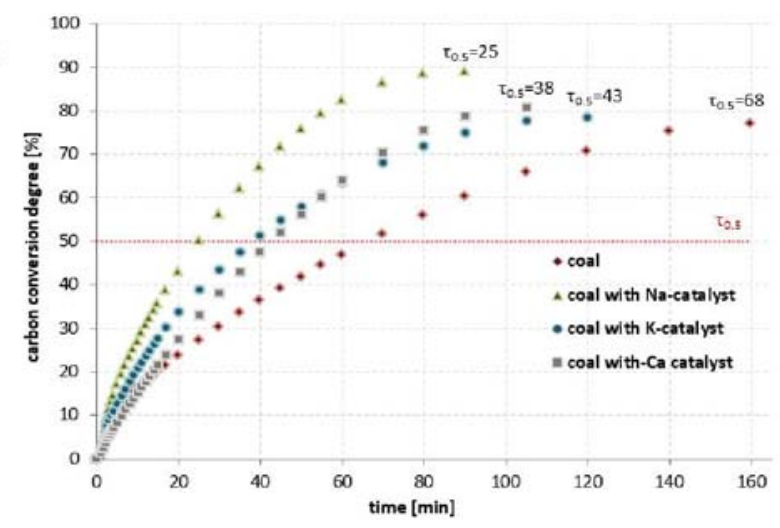

b)

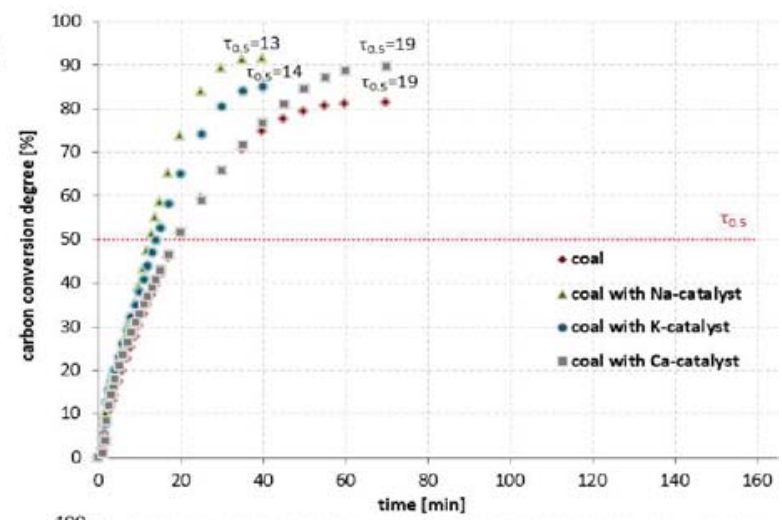

c)

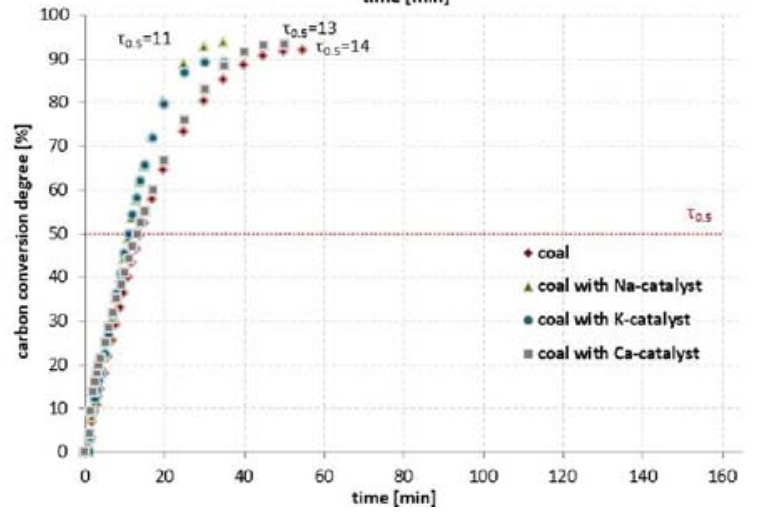

Figure 3. Changes in carbon conversion degrees during catalytic and non-catalytic gasification at: a) $800^{\circ} \mathrm{C}$; b) $900^{\circ} \mathrm{C}$; c) $950^{\circ} \mathrm{C}$

perature to $900{ }^{\circ} \mathrm{C}$ caused a significant reduction in the duration of the non-catalytic process $(70 \mathrm{~min})$, which was accompanied by an increase in the CCD to $81 \%$. Coal gasification with Ca-catalyst took the same amount of time, but the obtained CCD was significantly higher $(90 \%)$. In turn, gasification with Na- and K-catalysts lasted only $40 \mathrm{~min}$, and the obtained CCDs were 91 and $86 \%$, respectively. In addition, values of $\tau_{0.5}$ suggest that Ca-catalyst did not catalyse the initial part of the process (including pyrolysis stage) while other catalysts accelerated carbon conversion also at this stage. At 950 ${ }^{\circ} \mathrm{C}$, the differences between the examined measurements became less significant. The non-catalytic process lasted $55 \mathrm{~min}$, and CCD achieved over $90 \%$. The addition of Ca-catalyst had a very slight impact on both shortening the process time and increasing the CCD compared to measurement without a catalyst. In turn, the time of the gasification process with K-catalyst was shortened to $35 \mathrm{~min}$, but the CCD merely reached $90 \%$. Invariably, Na-catalyst was the most efficient - its presence caused that the process lasts only 35 minutes, and the achieved conversion degree was the highest (94\%). The values of $\tau_{0.5}$ confirmed the conclusions drawn above.

In summary, at $800^{\circ} \mathrm{C}$ all additives catalysed the conversion of carbon, and their efficiency was as follow: $\mathrm{Na}>\mathrm{Ca}>\mathrm{K}$; at $900^{\circ} \mathrm{C}$ catalytic effect was less significant but still observed, and the most efficient was Na-catalyst followed by $\mathrm{K}$ and Ca-catalysts; at $950^{\circ} \mathrm{C}$ only Na-catalyst showed visible catalytic effect. The activity of individual catalysts is consistent with the results obtained by the authors for the same types of catalysts introduced by wet impregnation method ${ }^{18}$. The weaker catalytic effect at high temperatures can be associated with the ash/catalyst melting, sintering or agglomeration ${ }^{19,20}$.

\section{Yield and composition of the resulting gas}

When assessing the impact of catalysts on the gas obtained, the attention should be paid on their efficiency and selectivity. As there were no significant differences in the total amounts of syngas obtained during measurements performed at specific temperatures, the assessment of catalysts will be based on the yields and percentages shares of main gas components formed during catalytic and non-catalytic gasification at various temperatures. The obtained results are presented in Figures 4 and 5, respectively.

Figure 4. shows that hydrogen was the main component of the resulting gas, followed by carbon monoxide, carbon dioxide and methane (formed mainly during the pyrolysis stage). As the process temperature increased, the yields of $\mathrm{CO}$ also increased at the expense of $\mathrm{CO}_{2}$, whereas yields of $\mathrm{H}_{2}$ remained at a similar level or slightly decreased. The amounts of gaseous components were also affected by the presence of catalysts. Addition of Na- and K-catalysts caused an increase in $\mathrm{CO}$ yields at all temperatures (at $800^{\circ} \mathrm{C}$ the highest $\mathrm{CO}$ yield was obtained by using Na-catalyst, but at higher temperatures effect of these catalysts was comparable), whereas Ca-catalyst resulted in slightly increased yield of $\mathrm{CO}$ only at $800^{\circ} \mathrm{C}$. These changes were accompanied by a decrease in $\mathrm{CO}_{2}$ yields. Consequently, the yields of incombustible $\mathrm{CO}_{2}$ form gasification with $\mathrm{K}$ - and $\mathrm{Na}$ catalysts were lower, while with Ca-catalyst (especially at $900-950^{\circ} \mathrm{C}$ ) higher than in the non-catalytic process. In turn, in most cases, the tested catalytic additives decreased yields of hydrogen. The only exception was the measurement with Na-catalyst at the lowest temperature during which the $\mathrm{H}_{2}$ yield was the highest. The effect of temperature or catalyst on methane yields was not observed.

The percentage compositions of the resulting gas (see Fig. 5.) confirm conclusions regarding the influence of temperature and catalysts, drawn based on components yields. Thus, the share of $\mathrm{H}_{2}$ was the highest and varied from $44 \%$ (gasification with Na-catalyst at $950^{\circ} \mathrm{C}$ ) to $59 \%$ (non-catalytic measurement at $800^{\circ} \mathrm{C}$ ). In the case of the second main gas component, $\mathrm{CO}$, its share varied in a broad range from $20.6 \%$ (non-catalytic measurement at $800^{\circ} \mathrm{C}$ ) to $42.6 \%$ (gasification with Na-catalyst at $950^{\circ} \mathrm{C}$ ), and this increase took place at the expense of $\mathrm{CO}_{2}$. Consequently, the share of carbon monoxide did not exceed $20 \%$. In turn, the contribution of methane into the resulting gas was slight and ranged between 0.8 and $4.7 \%$. 
a)

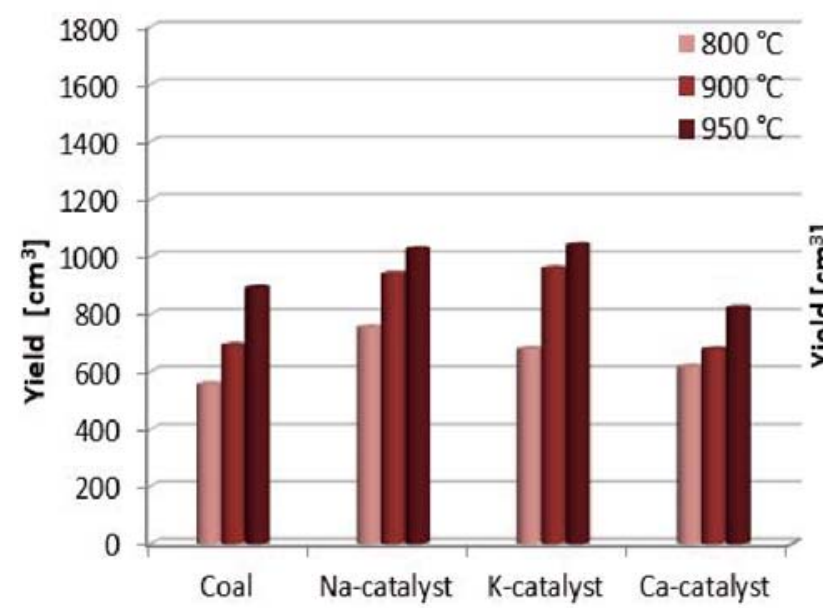

c)

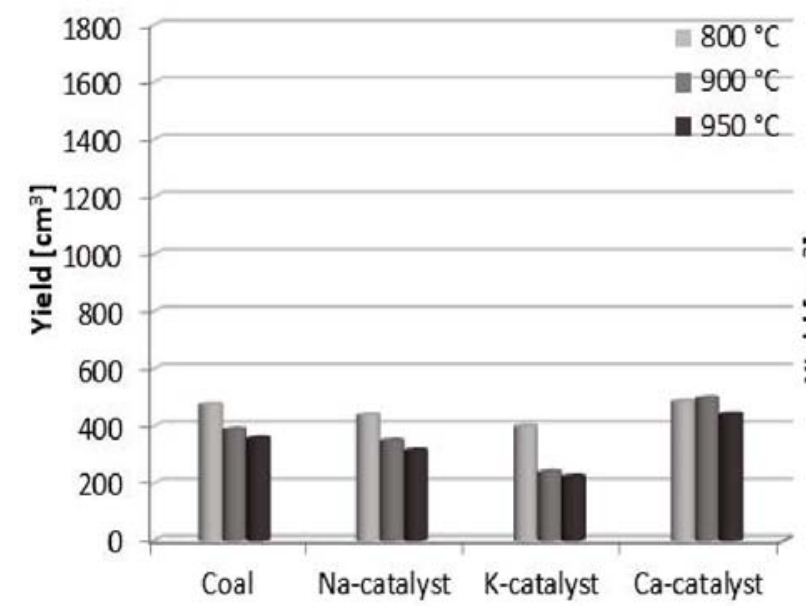

b)

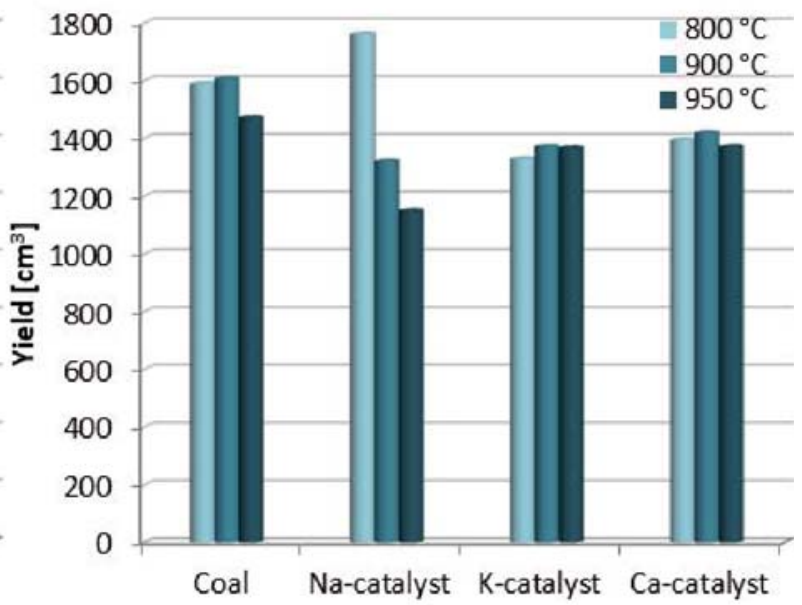

d)

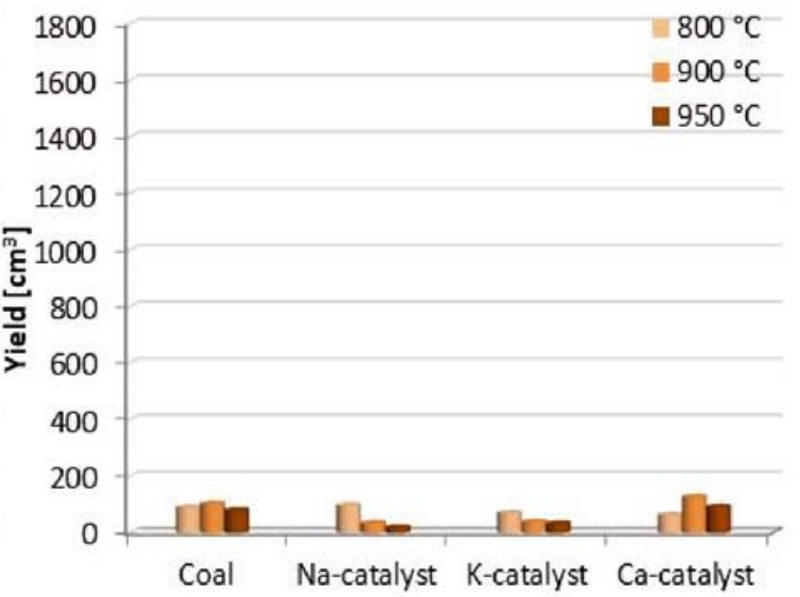

Figure 4. The yields of: a) $\mathrm{CO}$; b) $\mathrm{H}_{2}$; c) $\mathrm{CO}_{2}$; d) $\mathrm{CH}_{4}$ formed during catalytic and non-catalytic gasification at various temperatures

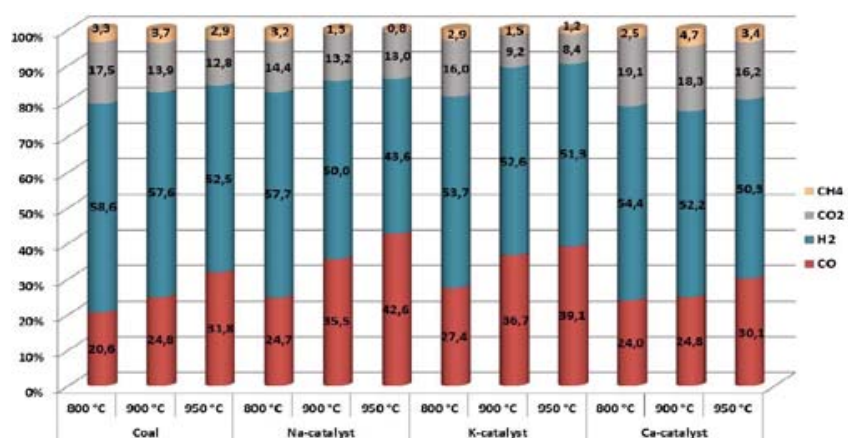

Figure 5. The share (vol\%) of main components of the resulting gas

Moreover, the presented results allow assessing the impact of catalysts on the main reactions in the steam gasification process, i.e. endothermic char-steam gasification reaction and exothermic water gas shift WGS reaction. As the temperature of the non-catalytic process increased, the char-steam reaction was dominant, while the WGS reaction was of less importance. Moreover, the decrease in $\mathrm{H}_{2}$ and $\mathrm{CO}_{2}$ yields suggest that mild-endothermic reverse WGS reaction took place. The Na catalysed the char-steam gasification reaction, mainly at low temperatures. However, at higher temperatures reverse WGS reaction seems to play more important role, resulting in lower $\mathrm{H}_{2}$ yields than in the non-catalytic gasificationas. In the case of K-catalyst, the importance of char-steam and reverse WGS reactions was similar, regardless of process temperature, as evidenced by similar yields of hydrogen. In turn, results obtained for gasification with $\mathrm{Ca}$-catalysts indicates that this additive catalysed $\mathrm{CO}_{2}$ formation reaction. Carbon dioxide is a product of, e.g. WGS reaction but no increase in $\mathrm{H}_{2}$ yields was observed compared to the non-catalytic process. Nevertheless, $\mathrm{H}_{2}$ yields were higher than in the case of other catalysts (except process with Na-catalyst at $800^{\circ} \mathrm{C}$ ) and remained at a constant level. Literature reports are proving that alkali metals are more active catalysts towards char-steam gasification reaction ${ }^{21}$ as well as that $\mathrm{Ca}$ compounds are efficient catalysts for WGS reaction ${ }^{22,23}$. Alkali metal compounds are also used as catalysts for WGS reaction but usually are enriched with promoter $^{24,25}$. Therefore, it can be concluded that $\mathrm{Ca}$ -catalyst more efficiently catalysed WGS reaction than $\mathrm{Na}$ or K-catalysts.

In summary, it can be concluded that from the point of view of obtaining $\mathrm{CO}$-rich gas, the K-and $\mathrm{Na}$-catalysts are the most efficient, while the use of Ca-catalyst is unfounded. In turn, when the goal is to obtain a hydrogen-rich gas, the process should be carried out at low temperatures in the presence of Na-catalyst. Otherwise, catalysts should not be used. 


\section{Kinetics analysis of $\mathrm{CO}$ and $\mathrm{H}_{2}$ formation reactions}

The results obtained so far gave a general insight into the coal gasification process. For a thorough analysis, the kinetics of $\mathrm{CO}$ and $\mathrm{H}_{2}$ formation reactions were investigated. Table 2 summarises the half-times $\tau_{X(t) 0.5}$ and rate constants $k$ of these reactions at analysed temperatures. of catalysts caused a reduction in the activation energy of both reactions, and this effect was the most significant by using Na-catalyst, followed by $\mathrm{K}$ - and Ca-catalysts. The kinetic parameters calculated based on GM and RPM were very similar to each other; however, some divergencies can be observed compared to results from the isoconversional

Table 2. Half times of $\mathrm{CO} / \mathrm{H}_{2}$ formation reaction and rate constants during gasification

\begin{tabular}{|c|c|c|c|c|c|c|c|}
\hline Sample & Gas & \multicolumn{2}{|c|}{$800^{\circ} \mathrm{C}$} & \multicolumn{2}{|c|}{$900^{\circ} \mathrm{C}$} & \multicolumn{2}{|c|}{$950^{\circ} \mathrm{C}$} \\
\hline \multicolumn{2}{|c|}{ component } & $\begin{array}{l}T_{X(t) 0.5} \\
{[\mathrm{~min}]}\end{array}$ & $\begin{array}{c}\mathrm{k}_{(\mathrm{RPM})} / \mathrm{k}_{(\mathrm{GM})} \\
{\left[10^{-2} \cdot \mathrm{min}^{-1}\right]}\end{array}$ & $\begin{array}{l}T_{X(t) 0.5} \\
{[\mathrm{~min}]}\end{array}$ & $\begin{array}{c}\mathrm{k}_{(\mathrm{RPM})} / \mathrm{k}_{(\mathrm{GM})} \\
{\left[10^{-2} \cdot \mathrm{min}^{-1}\right]}\end{array}$ & $\begin{array}{l}T_{X(t) 0.5} \\
{[\mathrm{~min}]}\end{array}$ & $\begin{array}{c}\mathrm{k}_{(\mathrm{RPM})} / \mathrm{k}_{(\mathrm{GM})} \\
{\left[10^{-2} \cdot \mathrm{min}^{-1}\right]}\end{array}$ \\
\hline Coal & $\begin{array}{l}\mathrm{CO} \\
\mathrm{H}_{2}\end{array}$ & $\begin{array}{l}35 \\
65\end{array}$ & $\begin{array}{l}1.36 / 1.62 \\
1.15 / 1.32\end{array}$ & $\begin{array}{l}12 \\
21\end{array}$ & $\begin{array}{l}4.05 / 4.81 \\
3.01 / 3.57\end{array}$ & $\begin{array}{r}9 \\
18\end{array}$ & $\begin{array}{l}5.66 / 6.70 \\
4.20 / 4.68\end{array}$ \\
\hline $\begin{array}{l}\text { Coal with: } \\
\text { Na-catalyst } \\
\text { K-catalyst } \\
\text { Ca-catalyst }\end{array}$ & $\begin{array}{c}\mathrm{CO} \\
\mathrm{H}_{2} \\
\mathrm{CO} \\
\mathrm{H}_{2} \\
\mathrm{CO} \\
\mathrm{H}_{2} \\
\end{array}$ & $\begin{array}{l}19 \\
28 \\
21 \\
35 \\
30 \\
44\end{array}$ & $\begin{array}{l}2.51 / 2.97 \\
2.00 / 2.36 \\
2.20 / 2.60 \\
1.65 / 1.95 \\
1.83 / 2.11 \\
1.29 / 1.49 \\
\end{array}$ & $\begin{array}{r}9 \\
14 \\
10 \\
16 \\
13 \\
18\end{array}$ & $\begin{array}{l}5.94 / 6.98 \\
5.06 / 6.00 \\
5.45 / 6.42 \\
4.13 / 4.87 \\
3.80 / 4.41 \\
3.25 / 3.80 \\
\end{array}$ & $\begin{array}{r}8 \\
11 \\
8 \\
11 \\
10 \\
13\end{array}$ & $\begin{array}{l}7.38 / 8.66 \\
6.15 / 7.26 \\
7.15 / 8.44 \\
6.05 / 7.16 \\
5.49 / 6.39 \\
4.25 / 5.02 \\
\end{array}$ \\
\hline
\end{tabular}

The lower values of $\tau_{X(t) 0.5}$ and higher values of $k$ of CO formation reaction evidenced that this reaction proceeded faster than $\mathrm{H}_{2}$ formation reaction. Moreover, the reaction rate constants calculated using GM were higher than those calculated based on RPM. Due to the endothermic nature of the gasification process, as the temperature increase, the half times of $\mathrm{CO}$ and $\mathrm{H}_{2}$ formation reactions decreased, while reaction rate constants increased. The effect of catalysts on these parameters is more complex and depends on the process temperature. At $800^{\circ} \mathrm{C}$, all additives catalysed both formation reactions, while the most efficient was Na-catalyst, followed by $\mathrm{K}$ - and Ca-catalysts. An increase in temperature to $900^{\circ} \mathrm{C}$ caused such a significant acceleration of the $\mathrm{CO}$ formation reaction during non-catalytic gasification that addition of Ca-catalyst was no longer justified. The other catalytic additives catalysed the $\mathrm{CO}$ formation reactions, and $\mathrm{Na}$ remained the most efficient catalyst. In turn, all tested additives resulted in acceleration of hydrogen formation reaction, and this effect was the most visible by using Na-catalyst, followed by K- and Ca-catalysts. Similar trends were observed at the highest temperature.

Summing up, Na- and K-catalysts accelerated $\mathrm{CO}$ and $\mathrm{H}_{2}$ formation reactions at all analysed temperatures. In turn, Ca-catalyst catalysed both of these reactions only at $800^{\circ} \mathrm{C}$, while at higher temperatures its catalytic effect was weak, and observed only towards the $\mathrm{H}_{2}$ formation reaction.

In the next step, the kinetic parameters (activation energy $E_{a}$ and pre-exponential factor $A$ ) of the $\mathrm{CO}$ and $\mathrm{H}_{2}$ formation reactions were calculated using the isoconversional method as well as RPM and GM. The results are summarised in Table 3 .

The values of $E_{a}$ of the $\mathrm{CO}$ formation reaction, calculated based on the isoconversional method, were lower than $E_{a}$ of $\mathrm{H}_{2}$ formation reaction. Moreover, the addition method. Firstly, in the non-catalytic process, values of $E_{a}$ and $A$ of $\mathrm{CO}$ formation reaction were higher than those of $\mathrm{H}_{2}$ formation reaction. The addition of catalysts caused a reduction in the kinetics parameters, especially in the case of $\mathrm{CO}$ formation reaction. As a result, the kinetic parameters of $\mathrm{CO}$ formation reaction during catalytic processes were lower than those of $\mathrm{H}_{2}$ formation reaction. Moreover, the most considerable reduction in the kinetic parameters of $\mathrm{CO}$ formation reaction was obtained by using $\mathrm{Na}$ - and $\mathrm{Ca}$-catalysts (comparable effect), while K-catalyst was the least efficient. In the case of $\mathrm{H}_{2}$ formation reaction, $\mathrm{Na}$-catalyst ensured the greatest reduction in kinetics parameters, whereas the catalytic effect of other additives was similar. Divergences in results calculated based on various models do not allow drawing unambiguous conclusions. However, it can be stated that the addition of catalysts caused a decrease in values of both kinetic parameters and that Na-catalyst reduced these parameters to the greatest extent.

\section{CONCLUSION}

The obtained results confirmed the catalytic effect of tested catalysts on the steam gasification process, especially at low temperatures. The addition of catalysts resulted in a reduction of process duration while increasing the carbon conversion degree. At $800^{\circ} \mathrm{C}$, the highest $\mathrm{CCD}$ was achieved during gasification with Na-catalyst, followed by Ca- and K-catalysts, whereas at the highest temperature, only Na-catalyst showed a visible catalytic effect on carbon conversion degree. However, it should be kept in mind that $\mathrm{CCD}$ is affected by all compounds containing carbon (including undesirable $\mathrm{CO}_{2}$ ). Therefore, to properly assess the effect of catalysts on the process, an analysis of yields and percentages shares of main gas components was ne-

Table 3. Kinetic parameters of $\mathrm{CO}$ and $\mathrm{H}_{2}$ formation reactions

\begin{tabular}{|c|c|c|c|c|c|}
\hline \multirow[t]{2}{*}{ Sample } & \multirow{2}{*}{$\begin{array}{c}\begin{array}{c}\text { Isoconvesional } \\
\text { method }\end{array} \\
\mathrm{E}_{\mathrm{a}(\mathrm{Co}) / \mathrm{E}_{\mathrm{a}\left(\mathrm{H}_{2}\right)}} \\
{[\mathrm{kJ} / \mathrm{mol}]}\end{array}$} & \multicolumn{2}{|c|}{ RPM } & \multicolumn{2}{|c|}{ GM } \\
\hline & & $\begin{array}{c}\mathrm{E}_{\mathrm{a}(\mathrm{CO})} / \mathrm{E}_{\mathrm{a}\left(\mathrm{H}_{2}\right)} \\
{[\mathrm{kJ} / \mathrm{mol}]}\end{array}$ & $\begin{array}{c}\mathrm{A}_{(\mathrm{CO})} / \mathrm{A}_{\left(\mathrm{H}_{2}\right)} \\
{\left[\mathrm{min}^{-1}\right]}\end{array}$ & $\begin{array}{c}\mathrm{E}_{\mathrm{a}(\mathrm{CO})} / \mathrm{E}_{\mathrm{a}\left(\mathrm{H}_{2}\right)} \\
{[\mathrm{kJ} / \mathrm{mol}]}\end{array}$ & $\begin{array}{c}\mathrm{A}_{(\mathrm{CO})} / \mathrm{A}_{\left(\mathrm{H}_{2}\right)} \\
{\left[\mathrm{min}^{-1}\right]}\end{array}$ \\
\hline $\begin{array}{l}\text { Coal with: } \\
\text { Na-catalyst } \\
\text { K-catalyst } \\
\text { Ca-catalyst }\end{array}$ & $\begin{array}{l}62.3 / 68.4 \\
73.4 / 84.1 \\
81.0 / 87.6\end{array}$ & $\begin{array}{l}78.9 / 84.3 \\
85.8 / 88.7 \\
79.2 / 87.3\end{array}$ & $\begin{array}{l}178.6 / 262.1 \\
346.0 / 350.0 \\
163.8 / 207.4\end{array}$ & $\begin{array}{l}78.3 / 84.6 \\
85.7 / 87.6 \\
79.9 / 88.2\end{array}$ & $\begin{array}{l}198.8 / 321.2 \\
366.0 / 400.9 \\
163.7 / 293.9\end{array}$ \\
\hline
\end{tabular}


cessary. The Na- and K-catalysts efficiently catalysed the $\mathrm{CO}$ formation reactions making that at all temperatures yields (and thus shares) of this gas were higher than in the non-catalytic process, whereas $\mathrm{CO}_{2}$ yields were lower. In turn, Ca-catalyst caused an increase in $\mathrm{CO}$ yield only at the lowest temperature, while regardless of temperature increased shares of incombustible $\mathrm{CO}_{2}$. Therefore, even though Ca-catalyst increased carbon conversion degree, it does not seem to be a suitable catalyst for the coal gasification process. In addition, the presence of catalysts in gasification measurements resulted in reduced yields of $\mathrm{H}_{2}$ (except measurements with Na-catalysts at $800{ }^{\circ} \mathrm{C}$ ), so if the process is designed to obtain hydrogen-rich gas, it should rather be run without catalysts. Adding catalyst, regardless of its type, caused also a reduction in values of both kinetic parameters (activation energy and pre-exponential factor) of the hydrogen and carbon monoxide formation reactions. The divergencies in the obtained results make it difficult to rank catalysts due to their efficiency in the reduction of kinetic parameters, but it can be stated that Na-catalyst reduced these parameters to the greatest extent. However, it should be kept in mind that reliable assessment of the gasification process cannot be based solely on kinetic parameters but should also take into account other parameters defining the process (half times and rate constants of gasification reactions at specific temperatures). In summary, the thermovolumetric method used in this work allowed a comprehensive assessment of the effect of physically mixed catalysts (both their efficiency and selectivity) on the coal gasification process with steam at various temperatures.

\section{ACKNOWLEDGEMENTS}

This paper was prepared thanks to funding from the Faculty of Energy and Fuels at the AGH University of Science and Technology, Grant no. 15.11.210.442

\section{LITERATURE CITED}

1. Monterroso, R., Fan, M., Argyle, M.D., Varga, K., Dyar, D., Tang, J., Sun, Q., Towler, B., Elliot, K.W. \& Kammen, D. (2014). Characterization of the mechanism of gasification of a powder river basin coal with a composite catalyst for producing desired syngases and liquids. Appl. Catal. A Gen. 475, 116-126. DOI: 10.1016/j.apcata.2014.01.007.

2. International Energy Agency, http://www.iea.org

3. Ding, L., Dai, Z., Wei, J., Zhou, Z. \& Yu, G. (2017). Catalytic effects of alkali carbonates on coal char gasification. $J$. Energy Inst. 90(4), 588-601. DOI: 10.1016/j.joei.2016.05.003.

4. Wang, J., Jiang, M., Yao, Y., Zhang, Y. \& Cao, J. (2009). Steam gasification of coal char catalyzed by $\mathrm{K}_{2} \mathrm{CO}_{3}$ for enhanced production of hydrogen without formation of methane. Fuel 88(9), 1572-1579. DOI: 10.1016/j.fuel.2008.12.017.

5. Chen, S.G. \& Yang, R.T. (1997). Unified mechanism of alkali and alkaline earth catalyzed gasification reactions of carbon by $\mathrm{CO}_{2}$ and $\mathrm{H}_{2} \mathrm{O}$. Energy Fuels $11(2), 421-427$. DOI: 10.1021/ef960099o.

6. Ohtsuka, Y. \& Asami, K. (1997). Highly active catalysts from inexpensive raw materials for coal gasification. Catal. Today 39(1-2), 111-125. DOI: 10.1016/S0920-5861(97)00093-X.

7. Karimi, A. \& Gray, M.R. (2011). Effectiveness and mobility of catalysts for gasification of bitumen coke. Fuel 90(1), 120-125. DOI: 10.1016/j.fuel.2010.07.032.

8. Kopyscinski, J., Rahman, R., Gupta, R., Mims, C. \& Hill, J. (2014). $\mathrm{K}_{2} \mathrm{CO}_{3}$ catalyzed $\mathrm{CO}_{2}$ gasifi cation of ash-free coal. Interactions of the catalyst with carbon in $\mathrm{N}_{2}$ and $\mathrm{CO}_{2}$ atmosphere. Fuel 117(Part B), 1181-1189. DOI: 10.1016/j. fuel.2013.07.030

9. Czerski, G., Zubek, K., Grzywacz, P. \& Porada, S. (2017). Effect of char preparation conditions on gasification in a carbon dioxide atmosphere. Energy Fuels 31(1), 815-823. DOI: 10.1021/acs.energyfuels.6b02139.

10. Porada, S., Czerski, G., Grzywacz, P., Makowska, D. \& Dziok, T. (2017). Comparison of the gasification of coals and their chars with $\mathrm{CO}_{2}$ based on the formation kinetics of gaseous products. Thermochim. Acta 653, 97-105. DOI: 10.1016/j. tca.2017.04.007.

11. Zubek, K., Czerski, G. \& Porada, S. (2018). Determination of optimal temperature and amount of catalysts based on alkali and alkaline earth metals for steam gasification process of bituminous coal. Thermochim. Acta 665, 60-69. DOI: $10.1016 /$ j.tca.2018.05.006.

12. Zubek, K., Czerski, G. \& Porada, S. (2017). Comparison of catalysts based on individual alkali and alkaline earth metals with their composites used for steam gasification of coal. Energy Fuels 32(5), 5684-5692. DOI: 10.1021/acs.energyfuels.7b03562.

13. Czerski G. (2018). Study on gasification kinetics by thermovolumetric and thermogravimetric methods. Przem. Chem. 97, 214-223. DOI: 10.15199/62.2018.2.6.

14. Porada, S., Dziok, T., Czerski, G., Grzywacz, P. \& Strugała, A. (2017). Examinations of Polish brown and hard coals in terms of their use in the steam gasification process. Mineral Resources Management 33(1), 15-34. DOI: 10.1515/gospo-2017-0007.

15. De Micco, G., Nasjleti, A. \& Bohe, A. E. (2012). Kinetics of the gasification of a Rio Turbio coal under different pyrolysis temperatures. Fuel 95, 537-543. DOI: 10.1016/j.fuel.2011.12.057.

16. Szekely, J., Evans, J.W. \& Sohn, H.Y. (1976). Gas-solid Reactions. New York, USA: Academic Press.

17. Bhatia, S.K. \& Perlmutter, D.D. (1980). A random pore model for fluid-solid reactions: I. Isothermal, kinetic control. AIChE J. 26(3), 379-386. DOI: 10.1002/aic.690260308.

18. Zubek, K., Czerski, G. \& Porada, S. (2017). The influence of catalytic additives on kinetics of coal gasification process. In E3S Web of Conferences 14 (02012), 1-10. EDP Sciences. Retrieved March 15, 2017, from http://www.e3s-conferences. org. DOI: doi.org/10.1051/e3sconf/20171402012.

19. Ding, L., Zhang, Y., Wang, Z., Huang, J. \& Fang, Y. (2014). Interaction and its induced inhibiting or synergistic effects during co-gasification of coal char and biomass char. Bioresour. Technol. 173, 11-20. DOI: 10.1016/j.biortech.2014.09.007.

20. Yamashita, H., Nomura, M. \& Tomita, A. (1992). Local structures of metals dispersed on coal. 4. Local structure of calcium species on coal after heat treatment and carbon dioxide gasification. Energy Fuels 6(5), 656-661. DOI: 10.1021/ ef00035a018.

21. Huang, X., Zhang, F., Fan, M. \& Wang, Y. (2015). Catalytic Coal Gasification. Sustainable Catalytic Processes, 179-199. DOI: 10.1016/B978-0-444-59567-6.00007-8.

22. Li, B., Wei, L., Yang, H., Wang, X. \& Chen, H. (2014). The enhancing mechanism of calcium oxide on water gas shift reaction for hydrogen production. Energy, 68, 248-254. DOI: 10.1016/j.energy.2014.02.088.

23. Sassmanova, V., Janouchova, R., Frantik, J., Machackova, I. \& Juchelkova, D. (2014). Influence of catalysts on watergas shift reaction and hydrogen recovery. IERI Procedia, 8, 164-169. DOI: 10.1016/j.ieri.2014.09.027.

24. Gnanamani, M.K., Jacobs, G., Shafer, W.D., Sparks, D.E., Hopps, S., Thomas, G.A. \& Davis, B.H. (2014). Low temperature water-gas shift reaction over alkali metal promoted cobalt carbide catalysts. Topics in Catalysis, 57(6-9), 612-618. DOI: $10.1007 / \mathrm{s} 11244-013-0219-7$.

25. Watanabe, R., Sakamoto, Y., Yamamuro, K., Tamura, S., Kikuchi, E. \& Sekine, Y. (2013). Role of alkali metal in a highly active $\mathrm{Pd} /$ alkali/ $\mathrm{Fe}_{2} \mathrm{O}_{3}$ catalyst for water gas shift reaction. Appl. Catalysis A: General, 457, 1-11. DOI: 10.1016/j.apcata.2013.03.010. 